\title{
Conflictos y derivaciones de un proceso de "turistización" en el centro histórico de Málaga
}

\author{
Lourdes Royo Naranjo | Dpto. Historia, Teoría y Composición Arquitectónicas, Universidad de Sevilla \\ URL de la contribución <www.iaph.es/revistaph/index.php/revistaph/article/view/3612>
}

El turismo masivo en los centros históricos no es en absoluto un tema de reciente actualidad, sin embargo, la intensidad de turistas que diariamente reciben las ciudades históricas y sus monumentos sí llega a ser una cuestión de enorme interés para la conservación y gestión del patrimonio. El desbordamiento de la capacidad de acogida de los destinos patrimoniales ocasiona daños irreparables a unos recursos culturales convertidos en base de la actividad turística actual (TROITIÑ VINUESA; TROITIÑO TORRALBA, 2016). Como consecuencia, la profusión de documentos e investigaciones que sobre este debate se han efectuado en las últimas décadas obedece, entre otras cuestiones, a un cambio en el modelo turístico y a la gestión de sus recursos. Un modelo diseñado de manera que en los centros históricos se concentran los problemas propios de cualquier aglomeración urbana pero elevados a una categoría en la que es fácil detectar conflictos y tensiones como consecuencia de la concentración de actividades terciarias en algunas zonas frente a la inexistencia en otras o el envejecimiento de la población y el agotamiento de un patrimonio cultural extremadamente frágil.

Una nueva situación que posiciona a las ciudades ante nuevos usos y su reconocimiento en un espacio urbano que se transforma para cumplir objetivos culturales y turísticos asociados al mismo tiempo a los valores de la ciudad histórica. Sin embargo, la delgada y delicada línea que separa el disfrute turístico y por ende aquellos efectos positivos recibidos de tal actividad también generan una serie de cuestiones oscuras y negativas asociadas esta vez a fenómenos como la turistización del patrimonio.

En este panorama, la ciudad histórica de Málaga se convierte en un claro ejemplo al que acudir como caso de estudio para entender un fenómeno que arranca con la creación e invento como destino cultural con marca propia y que empieza a recoger sus frutos.

Llegados a este punto, es importante destacar el considerable volúmen de aportaciones a la literatura científica sobre este tema (CASTRO LEÓN, 2005; DE ESTEBAN, 2008; MARTOS, 2016; TOSELLI, 2006; VELASCO GONZÁLEZ, 2009) que marcan la atención en torno a los aspectos positivos y negativos del uso y abuso turístico del patrimonio cultural en las ciudades históricas. En realidad, esta circustancia radica en la distribución que la propia industria ejerce sobre la ciudad, configurando una ciudad turística que se concentra en una parte bastante pequeña de la ciudad histórica y en su configuración influyen factores de naturaleza diversa: históricos, promocionales, simbólicos, urbanísticos, etc. (CALLE, 2002). Aunque se percibe un avance en la valorización e interpretación del patrimonio cultural como recurso turístico, existen serias dificultades para adecuar los centros históricos a la función turística, pues qué duda cabe de que la ciudad turística es una parte de la ciudad histórica no siempre bien gestionada, pero estrechamente conectada entre los circuitos de carácter turístico y los grandes hitos de referencia cultural. Tal es así que una de las mayores oportunidades que el turismo ofrece a los centros históricos es la recuperación y puesta en valor de un patrimonio urbanístico (TROITIÑO VINUESA; TROITIÑO TORRALBA, 2009).

Nuevas situaciones ante las que debemos buscar cierto equilibrio con el fin de evitar los conflictos que se suelen plantear entre el turismo y la conservación del patrimonio, en este caso de los centros históricos. Su mantenimiento constituye un reto para su pervivencia como realidad social aunque detectamos, sin embargo, cómo 
tales cuestiones no están resultando nada fáciles de poner en marcha en tanto en cuanto las políticas integradas de recuperación, más allá de las dimensiones arquitectónicas, deberían afrontar en profundidad cuestiones funcionales y sociales con el fin de evitar convertir los centros históricos en meros decorados urbanos o grandes museos abiertos. Este redescubrimiento de los centros históricos y su relación con el turismo cultural ha provocado como consecuencia un nuevo énfasis en las políticas de regeneración y rehabilitación de los mismos, así como la búsqueda de fuentes específicas para su financiación en paralelo a una recuperación patrimonial que de manera evidente refuerza la imagen y la identidad del destino, intentando establecer una diferenciación como marca patrimonial. Cobran especial importancia en este contexto los Fondos Europeos de Desarrollo Regional (FEDER), que a lo largo de dos décadas han proporcionado recursos económicos a regiones europeas especialmente débiles entre las que ha destacado Andalucía y, más concretamente, los centros históricos de sus ciudades.

Es aquí donde atendemos a la aparición de la estrategia de marketing cultural que ya mencionaban Richards y Wilson (2006), aplicada de forma directa para el beneficio de la industria del turismo de modo que patrimonio urbano, cultura e imagen se unen para ofrecer un producto completo, atractivo e inequívocamente focalizado hacia la difusión de una interpretación muy concreta de la realidad patrimonial de los centros históricos considerados. El sector cultural se ve abocado a renovar los antiguos modelos de gestión cultural, en busca de una integración de la profesionalización y la orientación empresarial, con un esfuerzo por no perder la identidad en su discurso patrimonial renovado, que busca y prioriza objetivos económicos y por tanto el retorno de la inversión pública y privada.

El marketing aplicado a la cultura o marketing cultural se presenta como herramienta de gestión empresarial imprescindible para el diseño de nuevas estrategias y políticas de promoción, comercialización, difusión y comunicación. En este nuevo escenario, el turista apa-

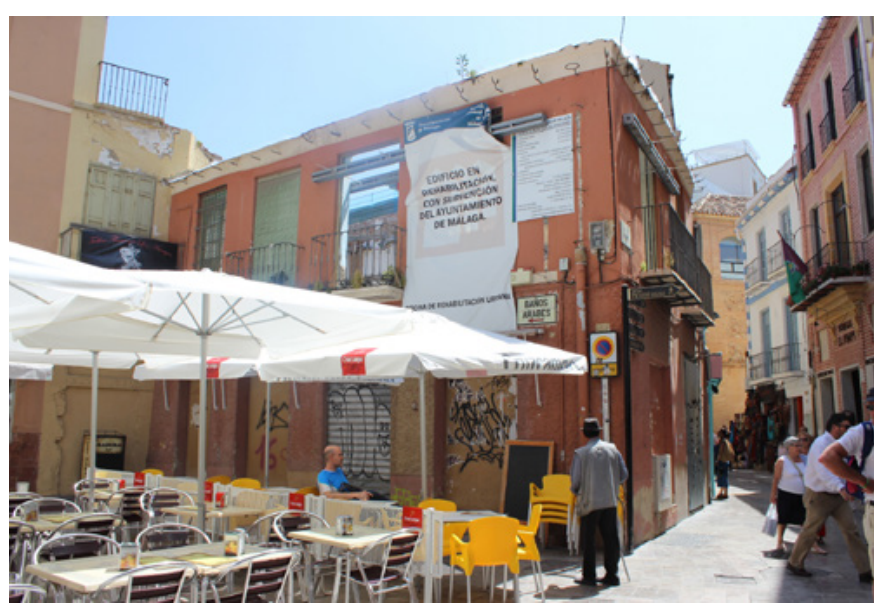

Centro histórico de Málaga (calle Granada)

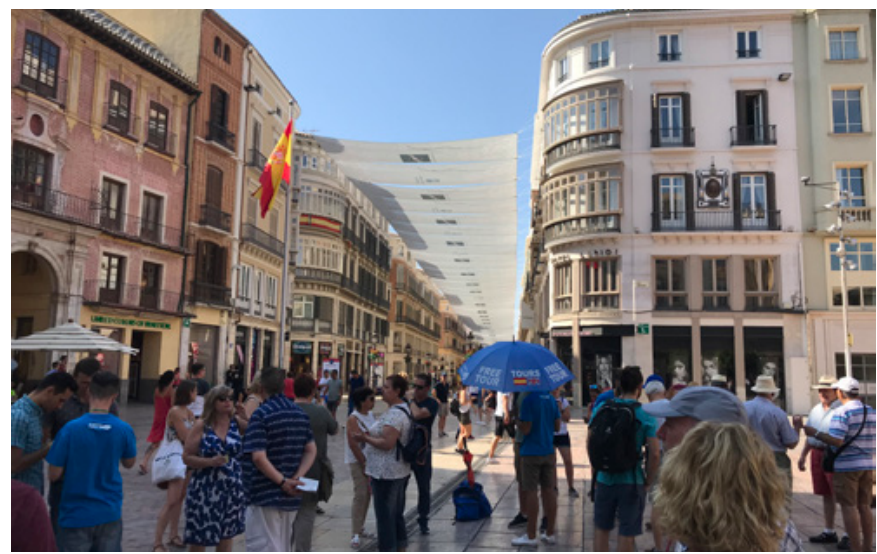

Turistas en la Plaza de la Constitución, Málaga. 2019

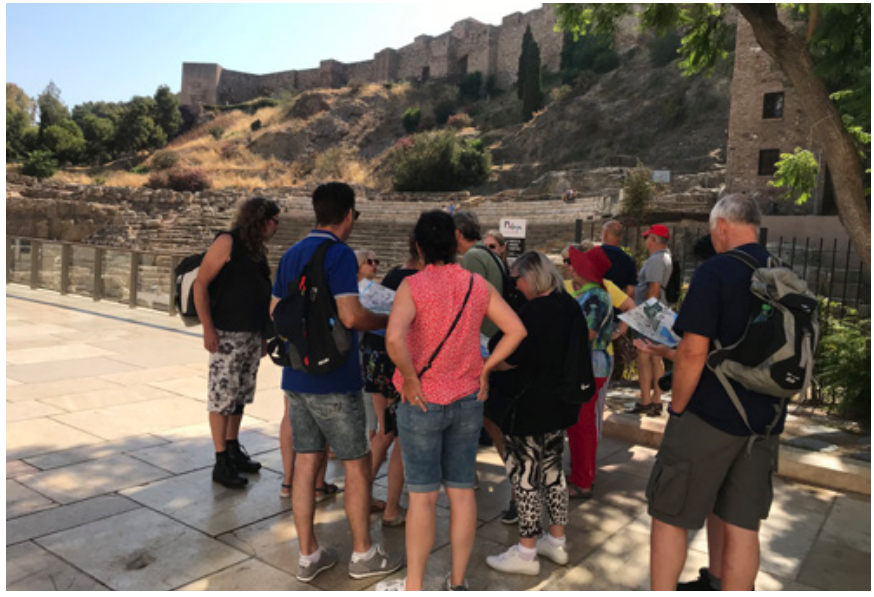

Turistas en el Teatro Romano de Málaga, 2019 | fotos Lourdes Royo 
a debate ¿Hay patrimonio sin comunidad? Despoblamiento, turistificación y patrimonio cultural

| coordina Jaime Jover Báez

rece como consumidor de bienes y servicios culturales y su presencia dinamiza los diversos sectores de actividad que generan riqueza y empleo al mismo tiempo que introduce nuevas modalidades en el consumo y en el uso de las ciudades, desarrollando ramas como la hostelería, restauración, transporte, comercio, servicios de ocio o recreo, así como otros sectores de actividad en un segundo orden orientados al turista.

De manera teórica sabemos que los centros históricos se caracterizan por ser espacios intensamente vividos por sus ciudadanos con carácter multifuncional, dada la gran diversidad de actividades que en ellos conviven, así como por la heterogeneidad que presentan a nivel social, fruto de las continuas transformaciones de la propia ciudad a lo largo del tiempo y los valores culturales asociados (TROITIÑO, 2005).

Cualidades que a propósito de nuestro caso de estudio están desapareciendo como consecuencia de un fuerte proceso de turistización en el que se ve inmerso su centro histórico y cuyos efectos más visibles han afectado a la economía local, al medio ambiente, al paisaje urbano $y$, sobre todo, a la vida cotidiana, estando estos impactos turísticos estrechamente ligados al volumen de la afluencia de visitantes fruto del crecimiento del turismo masivo (ROYO NARANJO; ARMENTA, 2016) y a la gestión de dichas actividades.

La característica fundamental que evidencia un problema de crisis de convivencia con la actividad turística es la desaparición de la vida residencial, el progresivo abandono de las viviendas del entorno, pues la presión del turismo una vez superados ciertos límites pueden incitar, en el caso de los centros históricos, a que la población residente los abandone, provocando procesos de despoblación, rupturas de equilibrio social y desapego patrimonial (TROTIÑO VINUESA; TROITIÑO TORRALBA, 2010).

Un hecho motivado por los continuos cambios de uso de los edificios que se rehabilitan para uso hotelero, la falta de comercios de abastecimiento primario en la zona y la dificultad de accesibilidad y tránsito consecuencia del elevado flujo turístico. Un tejido social heterogéneo que se va deteriorando progresivamente, disminuyendo la población vecinal a favor del visitante-espectador y consumista temporal. De este modo, la vida del barrio es suplantada por "escenarios" teatralizados diseñados para el turista-consumidor con los que el ciudadano malagueño no se identifica. Un proceso acompañado inevitablemente de una pérdida de la calidad, ya no sólo en la vida diaria del residente, sino para el propio turista que ni siquiera podrá disfrutar de la experiencia, ya que la estructura física de la calle no tiene suficiente capacidad para acoger el elevado número de peatones, coches, autobuses, bicicletas y segways que tienen que compartir este espacio tan limitado en algunos tramos del centro histórico de Málaga.

El valor social del centro histórico se hace eco de la realidad que vive su patrimonio, hoy en verdadero peligro. Asociaciones y grupos vecinales han fomentado el debate que a pie de calle se hace patente con agrupaciones como la Asociación en Defensa del Patrimonio Industrial de Málaga, Málaga Duele, Málaga Monumental, Pinturas Murales de Málaga, Salvemos Málaga, Se Vende Calle o Torre Vigía son algunos de ellos, pero no todos. Páginas web y blogs personales como Blog Edifeicios, Málaga REC, entre otros.

\section{BIBLIOGRAFÍA}

- CALLE, M. (2002) La ciudad histórica como destino turístico. Barcelona: Ariel, 2002

- CASTRO LEÓN, J. F. (2005) La calidad como herramienta de gestión del turismo cultural. Pasos [en línea], n. ${ }^{\circ} 3,20005$, pp. 143-148 <http://www.pasosonline.org/Publicados/3105/ PS100105.pdf> [Consulta: 24/07/2019]

- ESTEBAN, J. (DE) (2008) Turismo cultura y medio ambiente en destinos urbanos. Madrid: Servicio de Publicaciones de la Universidad Rey Juan Carlos, 2008

- MARTOS, M. (2016) Herramientas para la gestión turística del patrimonio cultural. Madrid: Trea Ediciones, 2016

- RICHARDS, G.; WILSON, J. (2006) Developing Creativity in Tourist Experiences: A solutions to Serial Reproduction of 
Culture. Tourism Management, vol. 27, n. ${ }^{\circ}$ 6, 2006, pp. 12091223

- ROYO NARANJO, L. (2013) Turismo, desarrollo, arquitectura. La aventura de la modernidad. Sevilla: Consejería de Fomento y Vivienda, Junta de Andalucía, 2013

- ROYO NARANJO, L.; ESPINO HIDALGO, B. (DEL).; PÉREZ CANO, M. T.; MOSQUERA ADELL, E. (2015) Recuperación de centros históricos: Málaga, capital del turismo cultural urbano del S. XXI. En Impulso al desarrollo económico a través del Turismo: VIII jornadas de investigación en turismo. Sevilla Universidad de Sevilla, 2015, pp. 429-450 <https:// idus.us.es/xmlui/bitstream/handle/11441/53031/royo-naranjo. pdf? sequence $=1>$ [Consulta: 23/07/2019]

- ROYO NARANJO, L.; ARMENTA, C. (2016) La turistización de los centros históricos y su protección patrimonial. el caso de la Carrera del Darro de Granada. En PARRINELLO, S. IV Convegno Internazionale sulla documentazione, conservazione e recupero del patrimonio architettonico e sulla tutela paesaggistica (Pavia, 6-7-8 Ottobre 2016). Firenze: Edifir, 2016

- ROYO NARANJO, L. (2017) Turismo, patrimonio y centros históricos. Estrategias de márketin cultural para la ciudad de Málaga. Arte y ciudad, n. ${ }^{\circ}$ 12, 2017, pp. 211-224.

- TOSELLI, C. (2006) Algunas reflexiones sobre el turismo cultural. Pasos [en línea], vol. 4, n. ${ }^{\circ} 2$, 2006, pp. 175-182 <http://www.pasosonline.org/Publicados/4206/PS040206.pdf> [Consulta: 24/07/2019]

- TROITIÑO VINUESA, M. A. (2003) La protección, recuperación y revitalización funcional de los centros históricos. Mediterráneo económico, n. 3, 2003 (Ejemplar dedicado a: Ciudades, arquitectura y espacio urbano/coord. por Horacio Capel Sáez), pp. 131-160

- TROITIÑO VINUESA, M. A. (2005) Potencialidades y límites en el uso turístico del patrimonio cultural en Instituto de Turismo Responsable. En Forum Mundial de las Culturas Diálogo sobre Turismo, Diversidad Cultural y Desarrollo Sostenible. Madrid: Instituto Turismo Responsable, 2005, pp. 83-88

- TROITIÑO VINUESA, M. A.; TROITIÑO TORRALBA, L. (2009) Turismo cultural y destinos patrimoniales en España: situación actual y retos de futuro. En MONDÉJAR JIMÉNEZ, J. A.; GÓMEZ BORJA, M. A. (coord.) Turismo cultural en ciudades Patrimonio de la Humanidad. Cuenca: Universidad de Castilla-La Mancha, Ediciones de la Universidad de CastillaLa Mancha, 2009, pp. 15-51 (Colección Humanidades, 101)

- TROITIÑO VINUESA, M. A.; TROITIÑO TORRALBA, L. (2010) Patrimonio y Turismo: una complementariedad necesaria en un contexto de uso responsable del patrimonio y cualificación de la visita. Patrimonio Cultural de España, n. ${ }^{\circ} 3$, 2010, pp. 89-108

- TROITIÑO VINUESA, M. A.; TROITIÑO TORRALBA, L.
(2016) Patrimonio y turismo: reflexión teórico-conceptual y una propuesta metodológica integradora aplicada al municipio de Carmona (Sevilla-España). Scripta Nova [en línea], vol. 20, n. ${ }^{\circ}$ 543, 2016, pp. 1-45 <http://revistes.ub.edu/index.php/ ScriptaNova/article/view/543> [Consulta: 23/07/2019]

- VALLS GIMÉNEZ, J. F. (2003) Las claves del mercado turístico. Cómo competir en el nuevo entorno. Bilbao: Deusto, 2003

- VELASCO GONZÁLEZ, M. (2009) Gestión turística del patrimonio cultural: enfoques para un desarrollo sostenible del turismo cultural. Cuadernos de Turismo [en línea], n. ${ }^{\circ}$ 23, 2009, pp. 237-253 <https://revistas.um.es/turismo/article/ view/70121> [Consulta: 23/07/2019] 